\title{
Symptoms, haemodynamics, and exercise capacity during long term treatment of chronic heart failure Experience with pirbuterol
}

\author{
J R DAWSON, R CANEPA-ANSON, P KUAN, S R REUBEN, P A POOLE-WILSON, \\ G C SUTTON
}

From East Birmingham District General Hospital, Birmingham; and Hillingdon Hospital, the National Heart
Hospital, and the Cardiothoracic Institute, London

SUMMARY An open study of long term treatment with an oral beta ${ }_{2}$ agonist (pirbuterol $20 \mathrm{mg}$ three times daily) was undertaken in 63 patients with severe chronic heart failure. During three months of treatment 20 (32\%) patients died, of whom 16 were taking the drug at the time of death. Mortality was related to initial functional class (New York Heart Association classification: $23 \%$ in grade III and $75 \%$ in grade IV). Concomitant treatment with digoxin did not affect mortality. The drug was well tolerated by most patients but unwanted side effects necessitated withdrawal of the drug in six (10\%). Thirty-five patients were continuing to take the drug after three months, of whom 22 reported symptomatic improvement and only four deterioration. There was a relation between symptomatic improvement and increase in exercise capacity. At initial haemodynamic assessment a single dose of pirbuterol increased the cardiac index by $34 \%$ and the stroke index by $21 \%$. Left ventricular filling pressure fell by $23 \%$ and systemic vascular resistance by $22 \%$. Haemodynamic reassessment after three months of continuous treatment in 29 patients showed maintained improvement in the group as a whole, although individual variation was considerable. There was no apparent relation between haemodynamic improvement and improvement in exercise duration and symptoms.

Severe heart failure has a poor prognosis. Identification of those patients who may derive benefit from treatment with a particular drug is not yet possible.

Severe chronic heart failure refractory to conventional treatment with diuretics and digitalis remains a major therapeutic problem. That vasodilator drugs in this group of patients produce acute haemodynamic benefit is well established ${ }^{1-9}$ but the clinical benefits of long term treatment with many of these agents are less certain and the natural history of the condition has not been shown to be altered. Some reports show sustained clinical and haemodynamic benefit ${ }^{2-69-11}$ but others do not, and haemodynamic tolerance develops in a proportion of patients treated with hydralazine, ${ }^{3}$ prazosin, ${ }^{1213}$ and isosorbide dinitrate. ${ }^{14}$ One uniform characteristic of these disparate reports is the small number of patients that comprise the study groups.

In this paper we report the results of an open study

Accepted for publication 7 June 1983 in a large series of 63 patients with severe chronic heart failure treated long term with pirbuterol, a drug currently marketed in Britain for the treatment of asthma. Pirbuterol is a beta ${ }_{2}$ adrenergic agonist with both vasodilator and positive inotropic properties. ${ }^{15}$

\section{Patients and methods}

Sixty-three patients (55 men and eight women) entered the study. Their ages ranged from 37-73 years (mean 60 years). The aetiology of heart failure was coronary artery disease in 50 patients, dilated cardiomyopathy in 11, and poor left ventricular function after aortic valve replacement in two. Fifty six of the patients were in sinus rhythm and seven were in atrial fibrillation.

Most patients were severely rather than moderately symptomatic; 12 were in grade IV (New York Heart 
Association classification), 43 in grade III, and eight in grade II. All patients had radiological evidence of cardiac enlargement (mean cardiothoracic ratio 0.56; range 0.5 to 0.75 ) and pulmonary venous congestion. All patients required diuretics for control of pulmonary congestion or dependent oedema or both; 57 were taking frusemide (mean daily dose $132 \mathrm{mg}$, range 40 to $500 \mathrm{mg}$ ) and 33 a potassium sparing diuretic (for example, spironolactone, triamterene, or amiloride). Twenty six patients in sinus rhythm and seven in atrial fibrillation were taking digoxin.

Pirbuterol was given for three months in a dose of $20 \mathrm{mg}$ three times daily, since our previous studies suggested that this was the optimal dose. ${ }^{1617}$

\section{CLINICAL ASSESSMENT}

The clinical condition of each patient was assessed monthly during the three month study period. Unwanted side effects were recorded. As far as possible patients were maintained on their prestudy diuretic treatment but necessary alterations were made at the discretion of the physician in charge of the patient. Other vasodilator drugs or digitalis were not added to the patient's treatment.

A chest $x$ ray film, electrocardiogram, and haematological and biochemical profiles were obtained before entry into the study and were repeated at each assessment.

\section{HAEMODYNAMIC MEASUREMENT}

Studies were performed in the morning without premedication. Right atrial, pulmonary artery, and wedge pressures were recorded using a balloon tip Swan-Ganz triple lumen catheter. Wedge pressure or pulmonary artery end-diastolic pressure was used as an indirect estimate of left ventricular filling pressure. Cardiac output was determined in triplicate by the thermodilution technique using the same catheter. Blood pressure was measured either with a sphygmomanometer or by an indwelling radial artery cannula. Mean blood pressure was either calculated as the diastolic blood pressure plus a third of the pulse pressure or derived from an electronically integrated record. Heart rate was obtained from a simultaneously recorded electrocardiogram and was averaged over 20 beats. Cardiac index $\left(1 / \mathrm{min}\right.$ per $\left.\mathrm{m}^{2}\right)$, stroke volume index (ml/beat per $\mathrm{m}^{2}$ ), and systemic vascular resistance (dyn $\left.\mathrm{s} / \mathrm{cm}^{5}\right)$ were calculated using standard formulae.

The following haemodynamic assessments were made:

Acute response-The acute haemodynamic response to pirbuterol was measured in all patients. The drug was given either as a single dose of 10 or $20 \mathrm{mg}(20$ patients) or as incremental doses to a maximum of 40 mg (43 patients).
Long term response-In 29 of the 35 patients who completed three months' treatment with pirbuterol haemodynamic measurements were repeated immediately before and three hours after a scheduled dose of the drug.

\section{EXERCISE TESTS}

Exercise testing was attempted in all patients immediately before the initial haemodynamic studies and again at the end of three months' continuous treatment with pirbuterol. Symptom limited graded exercise was performed on a treadmill, using either the Bruce protocol ${ }^{18}$ or, if the patient had a low exercise capacity, the Naughton protocol. ${ }^{19}$ The duration of exercise on the treadmill was recorded.

\section{DRUG PLASMA CONCENTRATION}

Plasma pirbuterol concentration was measured at the time of each set of haemodynamic measurements. Assays were performed using a gas chromatographic mass spectrometry method which measures the quantity of free unbound pirbuterol in the plasma. ${ }^{20}$ Results are expressed as mean \pm SEM. Differences between the means were compared by analysis of variance and by Student's paired $t$ test.

\section{Results}

\section{ACUTE RESPONSE}

The initial acute haemodynamic responses to pirbuterol in the 63 patients who entered the study are shown in Table 1 and Fig. 1. The results represent values for control and peak response. Cardiac index and stroke volume index were both increased $(p<0.001)$. Left ventricular filling pressure and calculated systemic vascular resistance were reduced $(\mathrm{p}<0.001)$. Heart rate and systolic blood pressure were unchanged but there was a reduction in diastolic blood pressure $(\mathbf{p}<0.01)$.

Table 1 Mean ( $\pm S E M)$ control and peak values for all measured and calculated haemodynamic variables in the 63 patients initially entered into the study

\begin{tabular}{|c|c|c|}
\hline Haemodymamic variables & $\begin{array}{l}\text { Control } \\
\text { response }\end{array}$ & Peak response \\
\hline $\begin{array}{l}\text { Heart rate (beats/min) } \\
\text { Systolic arterial pressure } \\
\quad(\mathbf{m m} \mathbf{H g})\end{array}$ & $\begin{array}{r}88 \pm 4 \\
120 \pm 3\end{array}$ & $\begin{array}{r}93 \pm 5 \\
118 \pm 3\end{array}$ \\
\hline $\begin{array}{l}\text { Diastolic arterial pressure } \\
\text { (mmHg) }\end{array}$ & $74 \pm 2$ & $69 \pm 2^{*}$ \\
\hline $\begin{array}{l}\text { Cardiac index }\left(1 / \text { min per } \mathrm{m}^{2}\right) \\
\text { Stroke volume index } \\
\left(\mathrm{ml} / \text { beat per } \mathrm{m}^{2}\right)\end{array}$ & $\begin{array}{l}2 \cdot 1 \pm 0 \cdot 1 \\
25 \pm 1\end{array}$ & $\begin{array}{l}2 \cdot 8 \pm 0 \cdot 1^{\star \star} \\
30 \pm 1^{\star \star}\end{array}$ \\
\hline $\begin{array}{l}\text { Left ventricular filling } \\
\text { pressure (mmHg) }\end{array}$ & $26 \pm 1$ & $20 \pm 1^{\star \star}$ \\
\hline $\begin{array}{l}\text { Systemic vascular resistance } \\
\left(\text { dyn } \mathrm{s} / \mathrm{cm}^{5}\right)\end{array}$ & $1830 \pm 70$ & $1410 \pm 65^{\star \star}$ \\
\hline
\end{tabular}

${ }^{\star} \mathrm{p}<0.01,{ }^{\star \star} \mathrm{p}<0.001$ (comparison with control). 

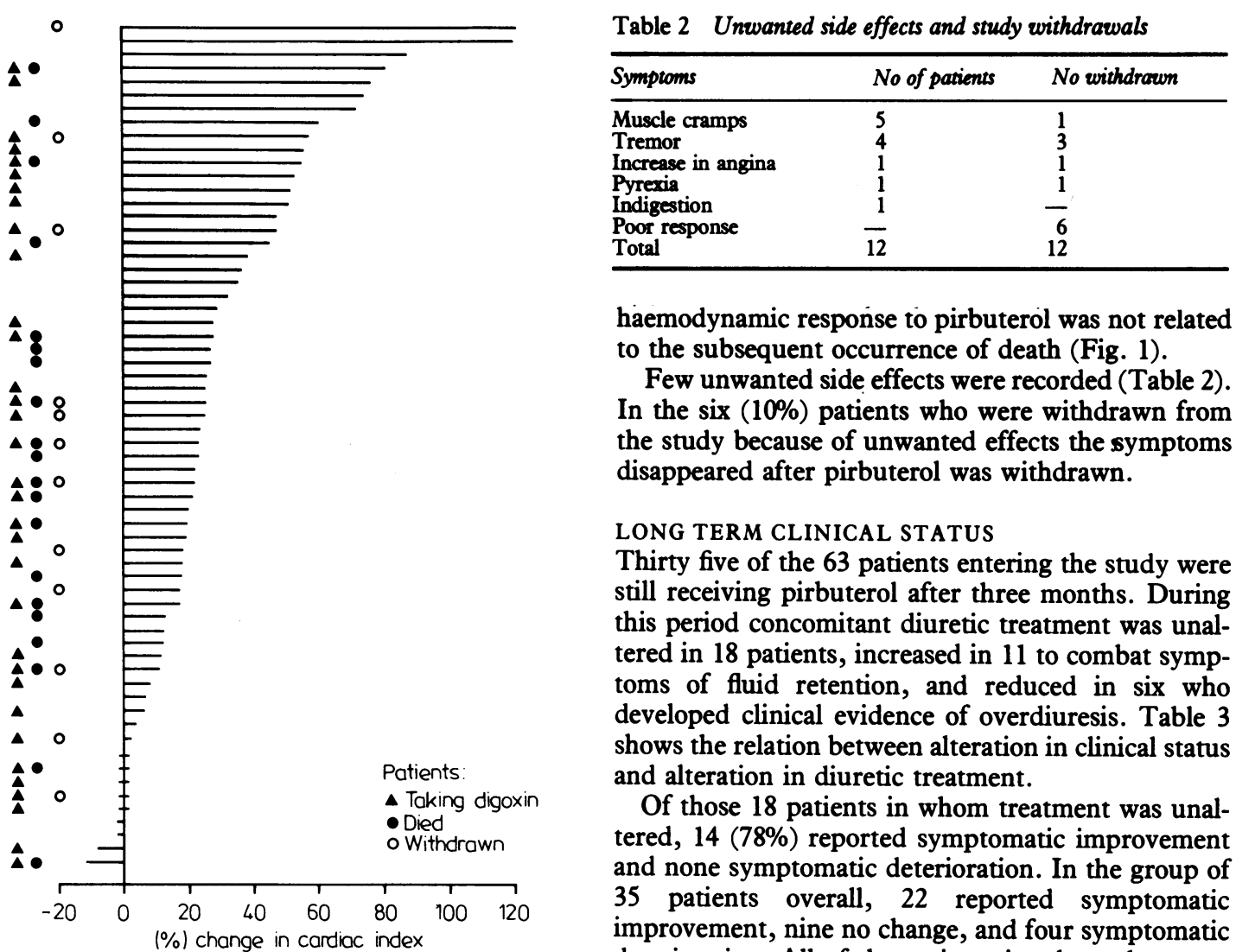

Fig. 1 Percentage change in cardiac index at peak response for individual patients in the acute haemodynamic study.

\section{WITHDRAWALS AND MORTALITY}

Sixty three patients entered the long term study. Twelve patients were withdrawn, six because of clinical deterioration. Four of these six patients died of progressive heart failure within days of stopping treatment with pirbuterol.

Twenty (32\%) patients died during the three month study period; 16 were taking pirbuterol at the time of death (Fig. 1). The cause of death was progressive heart failure in 15 patients, sudden heart failure in three, massive pulmonary embolism in one, and staphylococcal septicaemia in one. There was a relation between the initial clinical status of the patient (New York Heart Association classification grade) and the incidence of death. Of the 12 patients initially graded IV, nine (75\%) died; of the $\mathbf{4 3}$ graded III, 10 (23\%) died; and of those graded II only one $(12 \%)$ died. There were $12(36 \%)$ deaths in the 33 patients taking digoxin and eight (27\%) deaths in the 30 patients not taking digoxin. The initial haemodynamic response to pirbuterol was not related to the subsequent occurrence of death (Fig. 1).

Few unwanted side effects were recorded (Table 2). In the six (10\%) patients who were withdrawn from the study because of unwanted effects the symptoms disappeared after pirbuterol was withdrawn.

\section{LONG TERM CLINICAL STATUS}

Thirty five of the 63 patients entering the study were still receiving pirbuterol after three months. During this period concomitant diuretic treatment was unaltered in 18 patients, increased in 11 to combat symptoms of fluid retention, and reduced in six who developed clinical evidence of overdiuresis. Table 3 shows the relation between alteration in clinical status and alteration in diuretic treatment.

Of those 18 patients in whom treatment was unaltered, $14(78 \%)$ reported symptomatic improvement and none symptomatic deterioration. In the group of 35 patients overall, 22 reported symptomatic improvement, nine no change, and four symptomatic deterioration. All of the patients in whom there was symptomatic deterioration belonged to the subset in whom diuretics needed to be increased (Table 3).

\section{EXERCISE TESTS}

Thirty one of the 35 patients completing three months' treatment with pirbuterol had exercise tests before starting treatment and after three months. Exercise duration was increased in $23(74 \%)$ patients, decreased in seven (23\%), and unchanged in one. The mean $( \pm$ SEM) duration of exercise increased from $151 \pm 21 \mathrm{~s}$ to $281 \pm 49 \mathrm{~s}(\mathrm{p}<0.001)$. Fig. 2 summarises the results when the 31 patients are separated into

Table 3 Relation between change in diuretic treatment and change in clinical status during the three month treatment period

\begin{tabular}{llccc}
\hline Symptoms & \multicolumn{4}{l}{ Diuretic treatment } \\
\cline { 2 - 5 } & Decreased & Unchanged & Increased & Total \\
\hline Worse & 0 & 0 & 4 & 4 \\
Unchanged & 1 & 4 & 4 & 9 \\
Better & 5 & 14 & 3 & 22 \\
Total & 6 & 18 & 11 & 35 \\
\hline
\end{tabular}

$x^{2}=12.74, p<0.02$. 


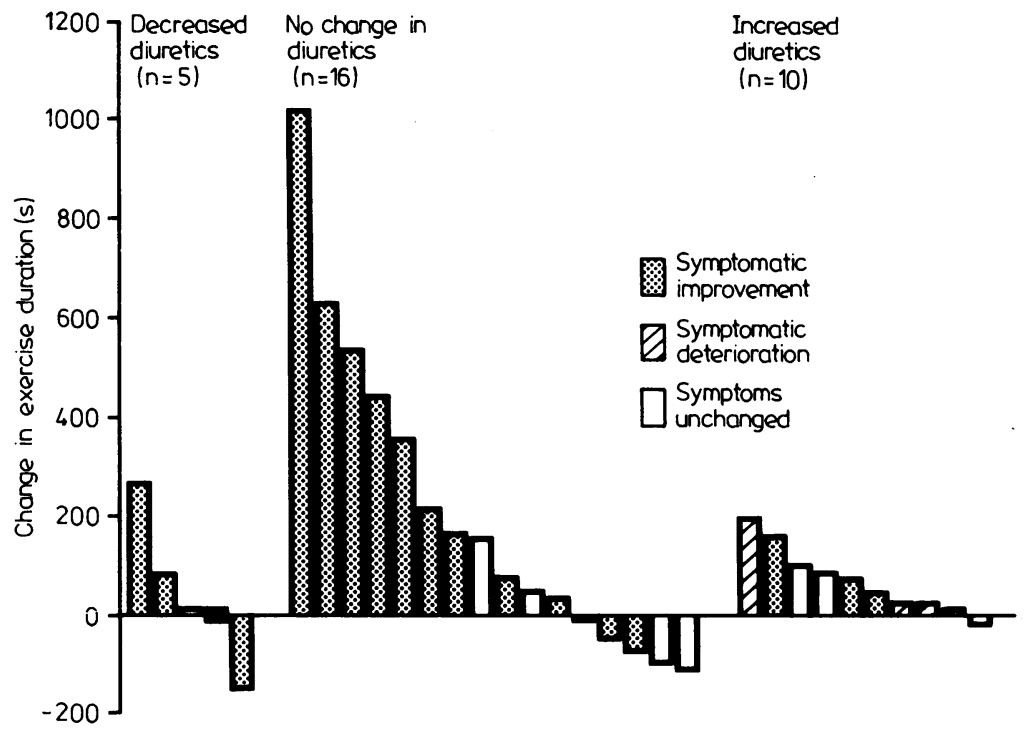

Fig. 2 Incremental changes in exercise duration in 31 patients after three months' treatment with pirbuterol. Concomitant diuretic treatment was increased $(n=10)$, decreased $(n=5)$, or unchanged $(n=16)$ during the treatment period. subgroups determined by whether or not concomitant diuretic treatment was altered during the three month study period. Fig. 2 shows that in general the largest increases in exercise duration occurred in those patients in whom diuretic treatment was unaltered or decreased and that those patients who reported improved symptoms tended to have greater increases in exercise duration than those in whom symptoms either deteriorated or were unchanged. The mean $( \pm$ SEM) values for exercise duration before treatment were not comparable between the three subgroups, being lowest $(89 \pm 23 \mathrm{~s})$ in those patients in whom diuretic treatment required increasing and highest $(303 \pm 131 \mathrm{~s})$ in those in whom diuretic treatment required reducing.

\section{LONG TERM HAEMODYNAMIC RESPONSE}

Twenty nine of the 35 patients who continued to take pirbuterol after three months were restudied. Table 4 and Fig. 3 show the results for the group overall; the values given are the control and peak response in the initial study and immediately before and three hours after a $20 \mathrm{mg}$ dose of pirbuterol in the long term study. The values before and after a scheduled dose after three months' treatment showed that haemodynamic benefit was maintained compared with the control response in the initial study. The concentration of pirbuterol at the time of the first measurement at three months was $18 \mathrm{ng} / \mathrm{ml}$ above that required for maximal haemodynamic response. For this reason the scheduled dose of pirbuterol did not bring about any further haemodynamic improvement.

The initial response to oral pirbuterol varied widely between patients, some showing little or no increase in cardiac index (Fig. 1). Similar variation was found in other haemodynamic variables. Fig. 4 shows the relation between the initial peak response (assessed as increase in cardiac index) and the response after a

Table 4 Mean ( $\pm S E M)$ values for all measured and calculated haemodynamic variables in the initial and repeat studies in 29 of the 35 patients who continued to take pirbuterol after three months' treatment

\begin{tabular}{|c|c|c|c|c|}
\hline & \multicolumn{2}{|l|}{ Acute study } & \multicolumn{2}{|c|}{ Three month study } \\
\hline & $\begin{array}{l}\text { Control } \\
\text { response }\end{array}$ & $\begin{array}{l}\text { Peak } \\
\text { response }\end{array}$ & $\begin{array}{l}\text { Predose } \\
\text { response }\end{array}$ & $\begin{array}{l}\text { Three hours } \\
\text { response }\end{array}$ \\
\hline $\begin{array}{l}\text { Heart rate (beats/min) } \\
\text { Systolic arterial pressure (mmHg) } \\
\text { Diastolic arterial pressure (mmHg) } \\
\left.\text { Cardiac index ( } 1 / \text { min per } \mathrm{m}^{2}\right) \\
\left.\text { Stroke volume index (ml/beat per } \mathrm{m}^{2}\right) \\
\text { Left ventricular filling pressure }\left(\mathrm{mmHg}^{2}\right) \\
\text { Systemic vascular resistance }\left(\mathrm{dyn} / \mathrm{cm}^{5}\right) \\
\text { Plasma pirbuterol concentration }(\mathrm{ng} / \mathrm{ml})\end{array}$ & $\begin{array}{c}86 \pm 3 \\
129 \pm 5 \\
76 \pm 2 \\
2 \cdot 2 \pm 0 \cdot 1 \\
28 \pm 2 \\
24 \pm 2 \\
1750 \pm 100 \\
0\end{array}$ & $\begin{array}{l}87 \pm 4 \\
124 \pm 4 \\
71 \pm 3^{\star \star} \\
3 \cdot 1 \pm 0 \cdot 2^{\star \star} \\
35 \pm 2^{\star \star \star} \\
17 \pm 2^{\star \star} \\
1330 \pm 95 \star \star \star \\
29 \pm 3\end{array}$ & $\begin{array}{l}81 \pm 3 \\
121 \pm 5^{\star} \\
70 \pm 3^{\star \star} \\
2 \cdot 5 \pm 0 \cdot 1^{\star \star \star} \\
34 \pm 2^{\star \star \star} \\
19 \pm 4^{\star} \\
1365 \pm 75^{\star \star \star} \\
18 \pm 2\end{array}$ & $\begin{array}{l}84 \pm 3 \\
120 \pm 4^{\star} \\
69 \pm 4^{\star \star} \\
2 \cdot 6 \pm 0 \cdot 1^{\star \star \star} \\
33 \pm 2^{\star \star \star} \\
19 \pm 2^{\star \star} \\
1360 \pm 80^{\star \star \star} \\
28 \pm 2\end{array}$ \\
\hline
\end{tabular}

${ }^{\star} \mathrm{p}<0.05,{ }^{\star \star} \mathrm{p}<0.01, \star \star \mathrm{p}<0.001$ (comparison with control response in acute study). 


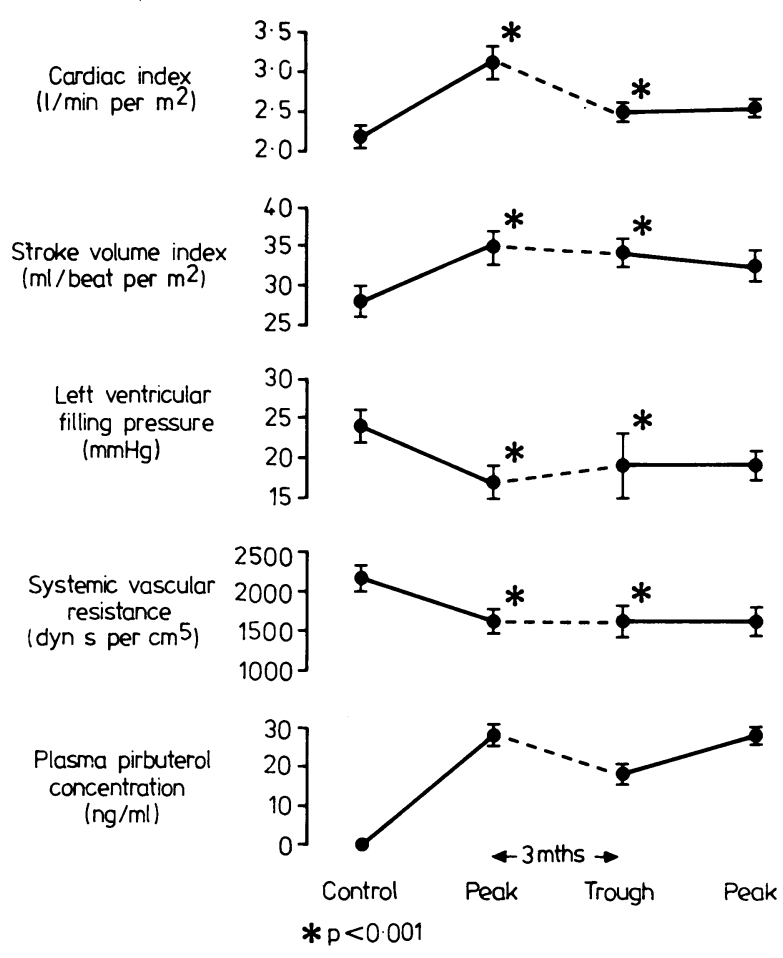

Fig. 3 Haemodymamic changes and plasma pirbuterol concentrations in the 29 patients who had haemodynamic assessment of the long term response to pirbuterol. All comparisons are with the control value in the initial acute study.

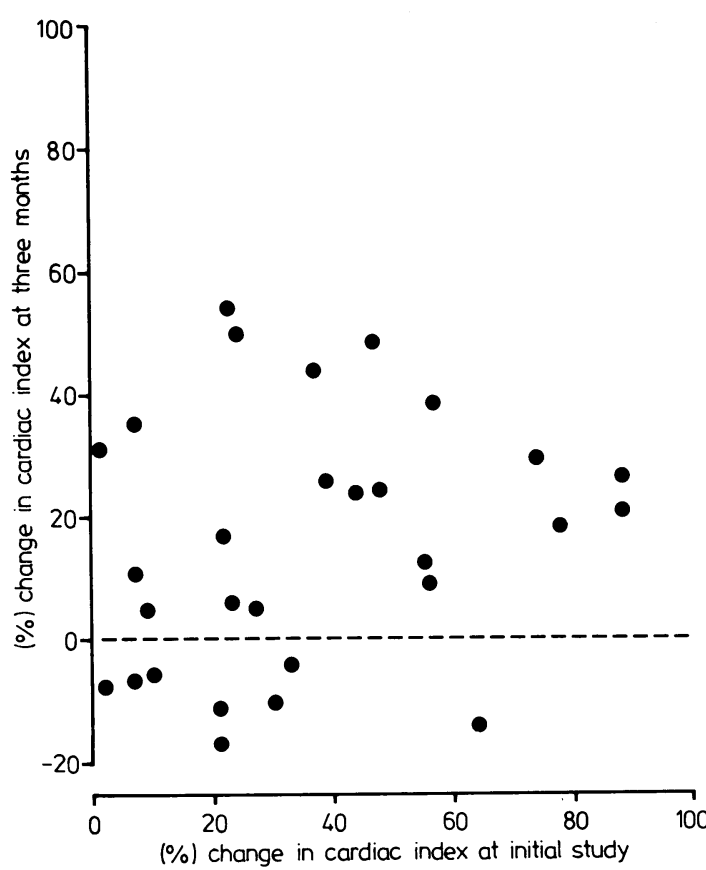

Fig. 4 Relation between the initial acute response and the long term response to pirbuterol in 29 patients. Percentage increase in cardiac index at peak response in the repeat study was compared with the initial control cardiac index. routine maintenance dose after three months' treatment with pirbuterol (increase in cardiac index compared with the initial control value). In general, the initial response did not allow prediction of the long term response.

Fig. 5 shows that in the 25 patients in whom both exercise and haemodynamic data were available there was only a tenuous relation $(r=0.29)$ between haemodynamic improvement and improvement in exercise duration. Separation into subgroups dependent on whether or not diuretic treatment was increased $(n=6)$, decreased $(n=4)$, or unchanged $(n=15, r=0.30)$ during the study period did not improve the relation (Fig. 5). Furthermore, Fig. 5 shows that for the whole group of 25 patients or for the subgroups there was no simple relation between haemodynamic change (as measured by alteration in stroke volume index) and change in the patients' symptoms.

\section{Discussion}

Pirbuterol is a beta ${ }_{2}$ adrenergic agonist with both positive inotropic and vasodilator properties. Such a combination of properties might on theoretical grounds be particularly advantageous in heart failure, where primary loss of myocardial contractility is linked with an increased systemic vascular resistance. Our initial 


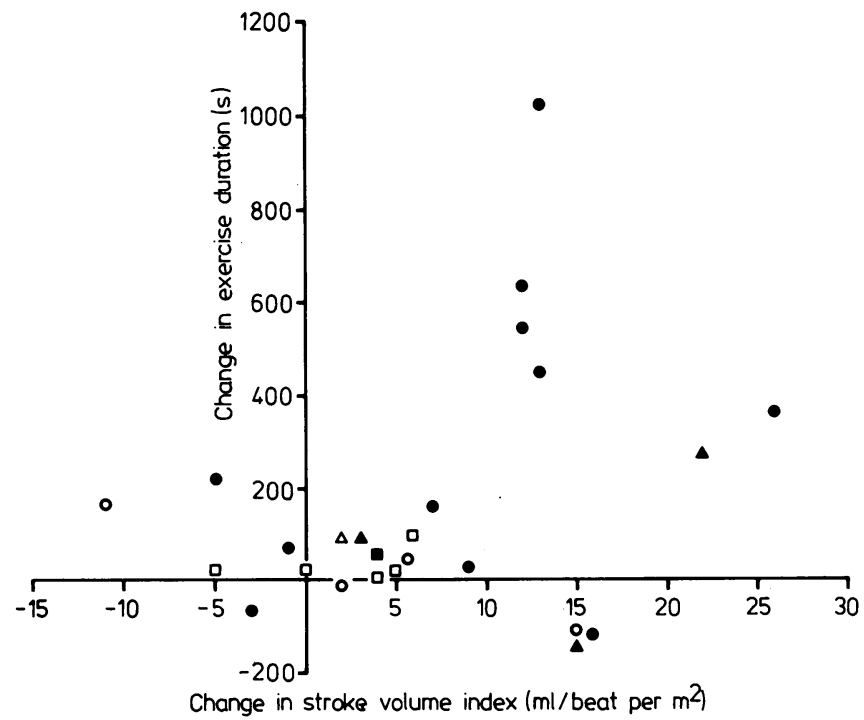

Fig. 5 Relations between change in stroke volume index and change in exercise duration in 25 patients after three month' treatment with pirbuterol. The open symbols denote patients in whom symptoms were either unchanged or deteriorated; the solid symbols those whose symptoms improved. The shape of the symbol indicates whether the patient's concomitant diuretic treatment was increased $\square$, decreased $\Delta \boldsymbol{\Delta}$, or unchanged $\bigcirc \bigcirc$ during the treatment period.

experience of the acute haemodynamic response to oral pirbuterol in patients with heart failure ${ }^{1617}$ prompted us to proceed to an open long term study of the drug.

In our study population the mortality rate at three months was $32 \%$. Although it is conceivable that the drug had a deleterious effect, because agents with positive inotropic properties may adversely affect survival by promoting myocardial ischaemia or cell damage, we think that this is unlikely. Similar mortality rates have been reported in groups of patients with heart failure treated with vasodilator drugs such as hydralazine ${ }^{21}$ and prazosin. ${ }^{22}$ Furthermore, it is known that pirbuterol does not increase myocardial oxygen consumption in patients at rest, ${ }^{23}$ reduce plasma potassium concentration when given chronically, ${ }^{24}$ or increase the frequency of arrhythmias. ${ }^{24}$ The high mortality in our study probably reflects the extreme severity of disease in this population rather than any adverse effect of pirbuterol, an interpretation consistent with the observation that most deaths occurred in those patients categorised in grade IV (New York Heart Association functional class)-that is, patients with the worst pump function and lowest cardiac reserve. This suggests that patients with grade IV symptoms are unsuitable for inclusion in long term drug trials designed to assess symptomatic response rather than mortality because the very high mortality rate (75\% in three months) will inevitably confuse the interpretation of the results. Mortality was not affected by the simultaneous administration of digoxin and pirbuterol. In patients receiving digoxin and pirbuterol the three month mortality was
$36 \%$ and with pi:hederol alone it was $27 \%$, but a greater proportion of patients taking digoxin had grade IV symptoms.

Pirbuterol was well tolerated by most patients. Unwanted effects, principally tremor and muscle cramp, were reported by 12 patients and resulted in withdrawal from treatment in six (10\%).

Diuretic treatment and salt intake were not rigidly controlled in this study. It is not feasible to do so in a large long term study of unselected patients with severe heart failure since some will deteriorate inexorably, requiring increasing diuretic dosage, while others may respond so well to treatment that failure to reduce diuretic dosage may result in overdiuresis and symptomatic deterioration. Of the 35 patients completing three months' treatment with pirbuterol, diuretic treatment was unchanged in 18 . These 18 patients comprised a subgroup in whom changes in symptomatic status can reasonably be assumed to be due to drug effect. Fourteen (78\%) of these patients reported symptomatic improvement and none symptomatic deterioration. In the group of 35 patients overall, only $22(63 \%)$ reported symptomatic improvement and four (11\%) symptomatic deterioration. Thus analyses of results of long term treatment which do not take into account alterations in diuretic treatment tend to have a diluting effect when benefit of treatment is being considered. Of those patients who had exercise tests before treatment and after three months, $74 \%$ had increased exercise duration. Overall the mean duration of exercise increased from 151 to $281 \mathrm{~s}$ which represents a substantial increase in work capacity because with both the Bruce and 
Naughton protocols the additional exercise time is at a higher workload. Because of the study design both a training and a placebo effect may have contributed to the observed increase in exercise duration. Fig. 2 shows that the greatest increases in exercise duration tended to occur in those patients in whom diuretic treatment was unchanged or decreased and also that there was a relation between increase in exercise duration and reported symptomatic improvement.

The acute haemodynamic effects of pirbuterol in 63 patients were to lower left ventricular filling pressure and systemic vascular resistance and increase cardiac index and stroke volume index. Heart rate and systolic and diastolic blood pressures were almost unchanged. Haemodynamic reassessment at three months in 29 patients showed continued haemodynamic improvement. There was no apparent relation between haemodynamic improvement and improvement in exercise duration and symptomatic status even when alterations in concomitant diuretic treatment were taken into account.

The overall finding of sustained effect in our group of patients is not in agreement with the findings of Colucci et al.$^{25}$ but is in accord with those of Awan et al. ${ }^{26}$ Both these groups also attempted to answer the question of whether the acute haemodynamic benefits of pirbuterol are maintained during long term treatment. Colucci et al. ${ }^{25}$ studied only 12 patients compared with our larger number. Their conclusions, based on radionuclide ejection fractions, were that there was complete loss of effect after one month. Five of these 12 patients, however, described symptomatic improvement, and recently the sensitivity of radionuclide ejection fractions in assessing treatment response has been challenged. ${ }^{27}$ In contrast, Awan et al. ${ }^{26}$ also using radionuclide ejection fractions found that in 12 patients haemodynamic benefit was maintained. The existence of subgroups of responders and non-responders identified in our larger number of patients shows that the apparently conflicting results of these two previous studies could have been obtained by chance selection of patients. Because they may have undue proportions of either responders or non-responders to a particular drug, small groups of patients may give rise to misleading conclusions if extrapolated to the general population of patients with heart failure. Some subsets of patients who would benefit may be denied treatment.

Prediction of long term haemodynamic effect, clinical response, and survival from the acute haemodynamic response was not possible (Figs. 1 and 4). Other investigators using different drugs ${ }^{14} 15$ have also been unable to predict which patients would show a sustained benefit. Extrapolation from the acute haemodynamic response in the supine patient at rest appears to be of extremely limited value. Such simplistic attempts at the prediction of the effect of sustained treatment with a drug do not take into consideration the numerous factors which affect the long term response to treatment of patients with severe chronic heart failure. ${ }^{28}$ To regard patient deterioration with chronic treatment to be solely the result of drug tolerance is to oversimplify a complex problem. The underlying pathological process may be progressive, and in some patients apparent treatment failure will simply reflect the natural history of heart failure. The powerful neurohumoral homeostatic mechanisms, such as either the renin-angiotensin-aldosterone system or the sympathetic nervous system, may override the effects of vasodilator drugs. The distribution of blood flow may be altered unfavourably by vasodilators.

This study shows that clinical and haemodynamic benefit is maintained long term in a substantial proportion of patients with severe chronic heart failure when treated with pirbuterol. Lack of sustained benefit in some patients may be the result of loss of drug effect, the natural history of disease, or other factors. The reasons for individual variation in response to pirbuterol need to be elucidated, just as they do with any drug. To answer the question of whether the natural history of heart failure can be altered in heterogeneous groups of patients with heart failure requires a large double blind placebo controlled trial. A rational basis for the selection of individual patients who would benefit from treatment remains a challenge.

We thank Pfizer Research for a supply of pirbuterol.

\section{References}

1 Guiha NH, Cohn JN, Mikulic E, Franciosa JA, Limas CJ. Treatment of refractory heart failure with infusion of nitroprusside. N Engl I Med 1974; 291: 587-92.

2 Fitchett DH, Marin-Neto JA, Oakley CM, Goodwin JF. Hydralazine in the management of left ventricular failure. Am $\mathcal{Y}$ Cardiol 1979; 44: 303-9.

3 Packer M, Meller J, Medina N, Yushak M, Gorlin R. Hemodynamic characterization of tolerance to long-term hydralazine therapy in severe chronic heart failure. $N$ Engl f Med 1982; 306: 57-62.

4 Chatterjee K, Ports TA, Brundage BH, Massie B, Holly AN, Parmley WW. Oral hydralazine in chronic heart failure: sustained beneficial hemodynamic effects. Ann Intern.Med 1980; 92: 600-4.

5 Williams DO, Bommer WJ, Miller RR, Amsterdam EA, Mason DT. Hemodynamic assessment of oral peripheral vasodilator therapy in chronic congestive heart failure: prolonged effectiveness of isosorbide dinitrate. Am $\mathcal{F}$ Cardiol 1977; 39: 84-90.

6 Miller RR, Awan NA, Maxwell KS, Mason DT. Sustained reduction of cardiac impedance and preload in 
congestive heart failure with the antihypertensive vasodilator, prazosin. $N$ Engl f Med 1977; 297: 303-7.

7 Davis R, Ribner HS, Keung E, Sonnenblick EH, LeJemtel TH. Treatment of chronic congestive heart failure with captopril, an oral inhibitor of angiotensinconverting enzyme. $N$ Engl f Med 1979; 301: 117-21.

8 Sharpe DN, Douglas JE, Coxon RJ, Long B. Low-dose captopril in chronic heart failure: acute haemodynamic effects and long-term treatment. Lancet 1980; ii: 1154-7.

9 Ader R, Chatterjee K, Ports T, Brundage B, Hiramatsu $B$, Parmley $W$. Immediate and sustained hemodynamic and clinical improvement in chronic heart failure by an oral angiotension-converting enzyme inhibitor. Circulation 1980; 61: 931-7.

10 Packer M, LeJemtel TH. Physiologic and pharmacologic determinants of vasodilator response: a conceptual framework for rational drug therapy for chronic heart failure. Prog Cardiovasc Dis 1982; 24: 275-92.

11 Franciosa JA. Effectiveness of long-term vasodilator administration in the treatment of chronic left ventricular failure. Prog Cardiovasc Dis 1982; 24: 319-30.

12 Packer M, Meller J, Gorlin R, Herman MV. Hemodynamic and clinical tachyphylaxis to prazosinmediated afterload reduction in severe chronic congestive heart failure. Circulation 1979; 59: 531-9.

13 Elkayam U, LeJemtel HT, Mathur M, et al. Marked early attenuation of hemodynamic effects of oral prazosin therapy in chronic congestive heart failure. Am $\mathcal{F}$ Cardiol 1979; 44: 540-5.

14 Thadani U, Manyari D, Parker JO, Fung H-L. Tolerance to the circulatory effects of oral isosorbide dinitrate: rate of development and cross-tolerance to glyceral trinitrate. Circulation 1980; 61: 526-35.

15 Taylor CR, Baird JRC, Blackburn KJ, et al. Comparative pharmacology and clinical efficacy of newer agents in treatment of heart failure. Am Heart f 1981; 102: 515-32.

16 Dawson JR, Canepa-Anson R, Kuan P, et al. Treatment of congestive heart failure with pirbuterol: acute haemodynamic responses. $\mathrm{Br} \mathrm{Med}$ F 1981; 282: 1423-6.

17 Canepa-Anson R, Dawson JR, Kuan P, et al. Single dose and dose-response studies with oral pirbuterol; a new beta-agonist in chronic heart failure. Am Heart $\mathcal{F}$ 1981; 102: $578-83$.
18 Bruce RA. Exercise testing of patients with coronary heart disease. Ann Clin Res 1971; 3: 323-32.

19 Patterson JA, Naughton J, Pietras RJ, Gunnar RM. Treadmill exercise in assessment of the functional capacity of patients with cardiac disease. Am $\mathcal{F}$ Cardiol 1972; 30: 757-62.

20 Falkner FC, McIlhenny HM. Selected ion monitoring assay for the bronchodilator pirbuterol. Biomed Mass Spectrom 1976; 3: 207-11.

21 Morand P, Lavigne G. Tolérance et accidents du traitement de l'insufficiance cardiaque sévère par la dihydralazine. Therapie 1980; 35: 645-8.

22 Rouleau J-L, Warnica JW, Burges JH. Prazosin and congestive heart failure: short- and long-term therapy. Am $\mathcal{Y}$ Med 1981; 71: 147-52.

23 Rude RE, Turi Z, Brown EJ, et al. Acute effects of oral pirbuterol on myocardial oxygen metabolism and systemic hemodynamics in chronic congestive heart failure. Circulation 1981; 64: 139-45.

24 Canepa-Anson R, Dawson JR, Frankl WS, et al. Beta-2 adrenoceptor agonists. Pharmacology, metabolic effects and arrhythmias. Eur Heart f 1982; 3 (suppl D): 129-34.

25 Colucci WS, Alexander RW, Williams GH, et al. Decreased lymphocyte beta-adrenergic-receptor density in patients with heart failure and tolerance to the betaadrenergic agonist pirbuterol. $N$ Engl f Med 1981; 305: 185-90.

26 Awan NA, Needham K, Evenson MK, et al. Therapeutic efficacy of oral pirbuterol in severe chronic congestive heart failure: acute hemodynamic and long-term ambulatory evaluation. Am Heart f 1981; 102: 555-63.

27 Firth BG, Dehmer GJ, Markham RV Jr, Willerson JT, Hillis LD. Assessment of vasodilator therapy in patients with severe congestive heart failure: limitations in measurements of left ventricular ejection fraction and volumes. Am 7 Cardiol 1982; 50: 954-9.

28 Zelis R, Flaim SF, Moskowitz RM, Nellis SH. How much can we expect from vasodilator therapy in congestive heart failure? Circulation 1979; 59: 1092-7.

Requests for reprints to Dr G C Sutton, Hillingdon Hospital, Uxbridge, Middlesex UB8 3NN. 